\title{
Evaluation of Metro Construction Emergency Management Capacity based on COWA Operator and Grey Clustering
}

\author{
J.X.Zhao ${ }^{\text {a }}$, M.M.Wang ${ }^{\text {b }}$ and D.D.Wu \\ School of Management, Qingdao Technological University, Qingdao, China \\ azhjxqdsd@163.com, blunwenzhyyx@126.com, c1170331391@qq.com
}

\begin{abstract}
Keywords: Emergency management; COWA operator; Grey clustering evaluation; Metro construction.

Abstract. From the point of view of improving the emergency management ability of metro construction, combining with the relevant measures of emergency management, the index system of emergency management ability of metro construction is established. Then, the weights of indexes are determined by the C-OWA operator, by using the grey theory, a grey clustering evaluation model, through the comprehensive evaluation of the concrete example to get the subway construction emergency management ability, and put forward reasonable suggestions for the emergency management ability of subway construction, provide a reference in the evaluation of the subway construction process first aid ability. Finally, the validity of the evaluation method is proved by an example, and some reasonable suggestions are given.
\end{abstract}

\section{Introduction}

At present, China's subway construction has entered the golden age of rapid development, but the frequent occurrence of emergencies, resulting in serious loss of property and personal safety in china. Therefore, the construction of emergency management capability has attracted more and more attention from all walks of life.

Scholars have paid much efforts to the emergency management of Metro Emergency .By sorting out research data, some achievements are found as follows:Lu Wengang research for metro emergency management from the subway emergency characteristics and the subway emergency management work of the actual situation[1].The establishment of a platform for the overall system architecture based on the metro emergency management information system by Wang qiankun [2].Han jia analyzed the city metro system contingency plans and put forward to improved urban subway emergency plan measures [3]. Deng yunfeng et al. by using used the method of G1 and Kappa analysis to evaluate urban emergency management ability[4].

In a word, the research on emergency management of subway mainly concentrated in the operation stage, therefore, based on the characteristics of emergencies in the construction process of our country in metro construction, established the gray clustering evaluation model based on grey theory evaluation of emergency management capability.

\section{The Construction of metro construction Emergency management index system}

With the cause of the accident of underground engineering and construction technology at home and abroad subway, danger and so on, the paper builds an index system of the emergency plan, emergency warning, emergency rescue, emergency information transmission speed, dealing with five aspects, according to the characteristics of China's construction of Metro Emergency process. Two indexes of seventeen levels are given, and the index system of emergency management capability of metro construction is established. The details are shown in figure 1. 


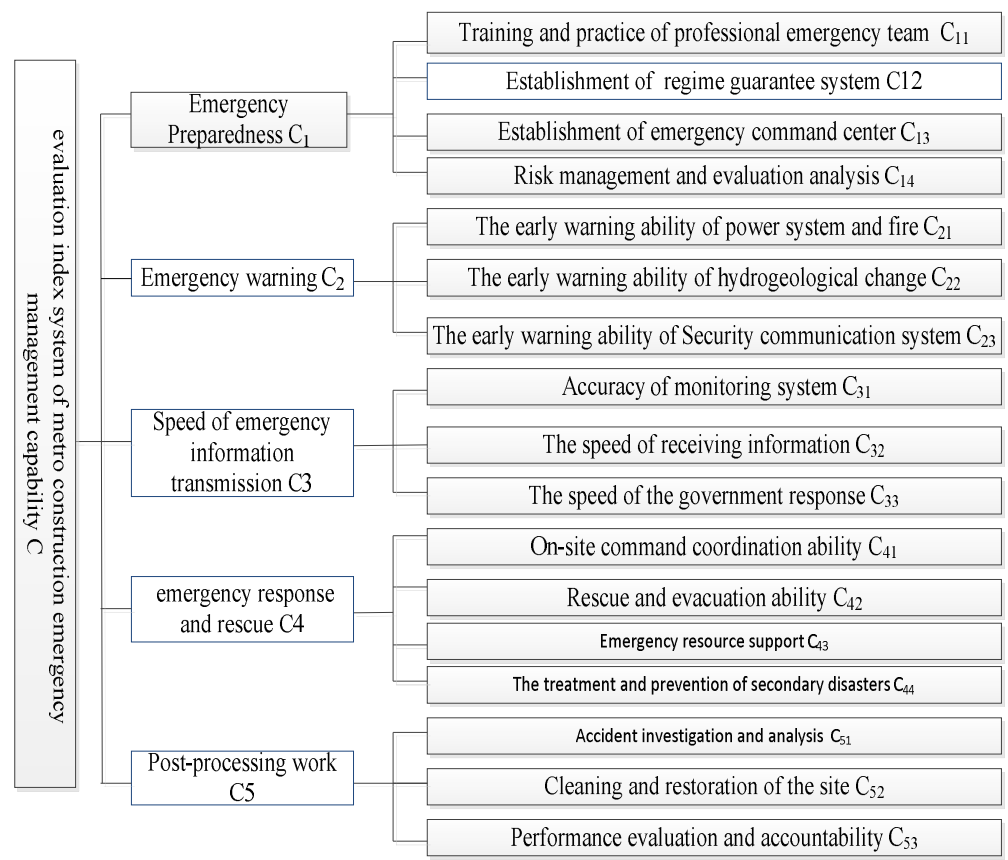

Fig. 1 The evaluation index system of emergencies management in metro construction

\section{The grey evaluation model of metro construction emergency management}

Determination of index weights based on COWA operator. General, assignment weight methods such as the entropy weight method, analytic hierarchy process (AHP). But these methods are processing data directly for assignment weight, that will result in a greater difference in the weighting results because of extreme values or extreme small values, and led to reduced weight distribution of scientific, in a less sample status. So that, in order to solve this problem, this paper introduced method CCOWA operator[5] . The steps of calculation are as follows.

(1) The decision-making data of evaluation index is $\left(a_{1}, a_{2}, \mathrm{~L} a_{i}, \mathrm{~L} a_{n}\right)$. Arrangement the decision-making data in the light of descending order, we get normalized matrix $\left(b_{1}, b_{2}, \mathrm{~L} b_{n}\right)$;

(2) The empowering vector of decision-making data is

$$
w_{j+1}=\frac{C_{n-1}^{j}}{\sum_{k=0}^{n-1} C_{n-1}^{k}}=\frac{C_{n-1}^{j}}{2^{n-1}} \quad j=0,1,2, \mathrm{~L} n-1
$$

(3) According to empowering vector $w_{j}$,empowerment the decision-making data $C_{j}$, then we can get absolute weight of index

$$
\varpi_{1}=\sum_{i=1}^{n} w_{j} \cdot b_{j} \quad w_{j} \in[0,1] j \in[1, n]
$$

(4) Calculate relative weights of the index, the specific calculation formula is

$$
w_{j}=\frac{\varpi_{i}}{\sum_{i=1}^{m} \varpi_{i}} \quad i=1,2, \mathrm{~L}, m
$$

\section{Grey evaluation model}

In the evaluation of the ability of emergency management in metro construction, people with limited cognitive ability of subway construction emergency management information is difficult to completely determine the range of parameters. It is usually called the grey number for its accurate range and fuzzy numerical number, expressed as " $\otimes$ ". The measure grade of the emergency management ability of the metro construction is divided into"excellent, good, generally good, qualified and unqualified", specific classified is shown in table 1. 
Table 1. emergency management ability performance measurement

\begin{tabular}{c|ccccc}
\hline grades & excellent & good & generally good & qualified & unqualified \\
\hline value & {$[10,8)$} & {$[8,6)$} & {$[6,4)$} & {$[4,2)$} & {$[2,0)$} \\
\hline
\end{tabular}

In the grey system theory, the point of the maximum degree of a kind of grey system is called the center point of the grey system. The paper divides the grey class is $U=(9,7,5,3,1)$, it is defined the maximum possible belongs, namely Grey quantitative threshold. The whitening weight function is the degree of "preference"to describe the grey number, and the model data is transformed from the grey number of incomplete information to the variables. The grey class and corresponding functions of whitening weight are shown in table 2.

Table 2. the grey class and corresponding functions of whitening weight the grey class $e \quad$ the grey number $\otimes_{e} \quad$ functions of whitening weight $f_{e}\left[d_{i j k}\right]$

$$
\begin{aligned}
& e=1 \quad \otimes_{1} \in[0,9, \infty] \quad f_{1}\left[d_{i j k}\right]= \begin{cases}\frac{d_{i j k}}{9}, & d_{i j k} \in[0,9] \\
1, & d_{i j k} \in[9, \infty] \\
0, & d_{i j k} \notin[0, \infty]\end{cases} \\
& e=2 \quad \otimes_{2} \in[0,7,14] \quad f_{2}\left[d_{i j k}\right]=\left\{\begin{array}{cc}
\frac{d_{i j k}}{7}, & d_{i j k} \in[0,7] \\
\frac{14-d_{i j k}}{7}, & d_{i j k} \in[7,14] \\
0, & d_{i j k} \notin[0,14]
\end{array}\right. \\
& e=3 \quad \otimes_{3} \in[0,5,10] \quad f_{3}\left[d_{i j k}\right]=\left\{\begin{array}{c}
\frac{d_{i j k}}{5}, d_{i j k} \in[0,5] \\
\frac{10-d_{i j k}}{5}, d_{i j k} \in[5,10] \\
0, \quad d_{i j k} \notin[0,10]
\end{array}\right. \\
& e=4 \quad \otimes_{4} \in[0,3,6] \quad f_{4}\left[d_{i j k}\right]=\left\{\begin{array}{c}
\frac{d_{i j k}}{3}, d_{i j k} \in[0,3] \\
\frac{6-d_{i j k}}{3}, d_{i j k} \in[3,6] \\
0, \quad d_{i j k} \notin[0,6]
\end{array}\right. \\
& e=5 \quad \otimes_{5} \in[0,1,2] \quad f_{1}\left[d_{i j k}\right]=\left\{\begin{array}{cc}
1, & d_{i j k} \in[0,1] \\
2-d_{i j k}, & d_{i j k} \in[1,2] \\
0, & d_{i j k} \notin[0,2]
\end{array}\right.
\end{aligned}
$$

\section{Algorithm principle and procedure}

This paper carried out the grey cluster evaluation on metro emergency management capacity, and taked the three level emergency management capability index system as an example, the specific implementation process is as follows:

(1)Establishment of grey evaluation matrix. 
According to the actual situation of the project, the emergency management ability is evaluated by the evaluation indicators with scores of experts.we can build the evaluation sample matrix $D_{i}=\left[d_{i j k}\right]_{s \times p}$, where $p$ is the number of expert, $d_{i j k}$ is a score of the third layer index $j$ under the second layer index $i$ that scored by the expert $k=1,2, \mathrm{~L} p$, the number of evaluation indices of matrix is $s$. Grey evaluation coefficient of index $C_{i j}$ is $X_{i j e}=\sum_{n=1}^{p} f_{e}\left[d_{i j k}\right]$. The comprehensive grey evaluation factor is $X_{i j}=\sum_{e=1}^{5} X_{i j e}$. The grey evaluation weight vector is $r_{i j e}=\frac{X_{i j e}}{X_{i j}}$, so grey evaluation weight matrix is $R_{i}=\left[\begin{array}{rrrrr}r_{i 11} & r_{i 12} & r_{i 13} & r_{i 14} & r_{i 15} \\ r_{i 21} & r_{i 22} & r_{i 23} & r_{i 24} & r_{i 25} \\ \mathrm{M} & \mathrm{M} & \mathrm{M} & \mathrm{M} & \mathrm{M} \\ r_{i j 1} & r_{i j 2} & r_{i j 3} & r_{i j 4} & r_{i j 5}\end{array}\right]$.

(2) Comprehensive Grey Evaluation

The paper definites grey comprehensive evaluation weight vector is $Z_{i}=\omega_{i} \cdot R_{i}$

So the comprehensive evaluation result is $M=\omega_{0} \cdot Z \quad Z=\left[Z_{1}, Z_{2}, \mathrm{~L} Z_{n}\right]^{T}$

assignments for each grey class according to the emergency management ability evaluation index value, Finally, we can get the comprehensive evaluation value $W=M U$

(3) The evaluation results are analyzed, and put forward the measures of emergency management. Comprehensive evaluation of emergency capability based on emergency capability measurement and cluster evaluation. The emergency ability level of every process and every level index in the process can be quantified. To enhance the ability of emergency management, and focus on improvement.

\section{Case analysis}

(1)Determination of Index Weight by COWA operator

Taking a metro construction section engineering as an example. Six experts are invited to empowerment the index system metro station emergency management capability. The weights of index as Table 3:

Table 3 expert evaluation value for $\mathrm{C}_{1} \sim \mathrm{C}_{5}$

\begin{tabular}{|c|c|c|c|c|c|c|}
\hline Index & Expert1 & Expert2 & Expert3 & Expert4 & Expert5 & Expert6 \\
\hline $\mathrm{C}_{1}$ & 9.0 & 8.0 & 8.8 & 8.3 & 9.0 & 8.6 \\
\hline $\mathrm{C}_{2}$ & 7.7 & 8.4 & 9.1 & 8.6 & 8.9 & 9.2 \\
\hline $\mathrm{C}_{3}$ & 7.2 & 8.2 & 8.1 & 7.6 & 8.3 & 8.7 \\
\hline $\mathrm{C}_{4}$ & 6.5 & 7.5 & 8.5 & 7.0 & 6.0 & 7.0 \\
\hline $\mathrm{C}_{5}$ & 7.3 & 7.0 & 6.5 & 8.1 & 7.6 & 8.0 \\
\hline
\end{tabular}

According to the Eq.1,Eq.2,Eq.3 ,the weights of second layer index is $\omega_{0}=\left(\begin{array}{lllll}0.205 & 0.23 & 0.195 & 0.18 & 0.19\end{array}\right)$. The weights of third layer index is

$\omega_{1}=\left(\begin{array}{llll}0.285 & 0.275 & 0.254 & 0.186\end{array}\right), \omega_{2}=\left(\begin{array}{lllll}0.355 & 0.312 & 0.333\end{array}\right) \omega_{3}=\left(\begin{array}{llll}0.320 & 0.330 & 0.350\end{array}\right)$,

$\omega_{4}=\left(\begin{array}{llll}0.232 & 0.280 & 0.303 & 0.185\end{array}\right) \omega_{5}=\left(\begin{array}{llll}0.318 & 0.344 & 0.337\end{array}\right)$

(2) Grey Cluster Assessment

With scores of experts, we can build the evaluation sample matrix

$$
\begin{aligned}
& D_{1}=\left[\begin{array}{lllllll}
8.0 & 7.5 & 9.0 & 9.5 & 7.0 & 8.0 & 8.5 \\
8.0 & 7.5 & 8.5 & 9.5 & 9.0 & 7.0 & 8.5 \\
7.5 & 8.0 & 8.5 & 9.0 & 9.5 & 8.0 & 8.5 \\
7.0 & 8.0 & 7.5 & 8.5 & 9.0 & 7.5 & 7.0
\end{array}\right], D_{2}=\left[\begin{array}{cccccccc}
7.5 & 8.0 & 9.0 & 9.5 & 8.5 & 8.0 & 7.5 \\
8.0 & 7.0 & 7.5 & 7.0 & 7.5 & 8.5 & 8.0 \\
8.5 & 9.0 & 8.0 & 8.5 & 8.0 & 7.5 & 7.0
\end{array}\right] \\
& D_{3}=\left[\begin{array}{llllllll}
7.5 & 7.0 & 6.5 & 8.0 & 8.5 & 9.0 & 7.0 \\
8.5 & 8.0 & 8.0 & 7.5 & 7.0 & 5.5 & 6.5 \\
8.0 & 6.5 & 7.0 & 7.5 & 7.0 & 8.0 & 8.5
\end{array}\right], D_{4}=\left[\begin{array}{ccccccc}
7.5 & 6.5 & 7.0 & 6.0 & 7.5 & 8.0 & 8.5 \\
8.0 & 7.0 & 7.5 & 6.5 & 5.5 & 6.0 & 5.5 \\
5 & 7.5 & 5.5 & 8.0 & 6.5 & 7.0 & 6.5 \\
5.5 & 7.0 & 6.5 & 8.0 & 8.5 & 7.5 & 6.0
\end{array}\right]
\end{aligned}
$$


$D_{5}=\left[\begin{array}{lllllll}8.0 & 8.5 & 9.0 & 8.0 & 7.5 & 7.0 & 7.5 \\ 7.5 & 8.0 & 7.0 & 8.0 & 8.0 & 8.5 & 7.0 \\ 7.0 & 8.5 & 7.5 & 7.0 & 7.5 & 8.0 & 7.5\end{array}\right]$

According to the Eq.4 we can get grey evaluation weight matrix

$$
\begin{aligned}
& R_{1}=\left[\begin{array}{lllll}
0.428 & 0.396 & 0.176 & 0 & 0 \\
0.441 & 0.394 & 0.165 & 0 & 0 \\
0.455 & 0.391 & 0.154 & 0 & 0 \\
0.394 & 0.404 & 0.202 & 0 & 0
\end{array}\right] R_{2}=\left[\begin{array}{lllll}
0.441 & 0.394 & 0.165 & 0 & 0 \\
0.381 & 0.407 & 0.212 & 0 & 0 \\
0.421 & 0.398 & 0.181 & 0 & 0
\end{array}\right] R_{3}=\left[\begin{array}{ccccc}
0.381 & 0.407 & 0.212 & 0 & 0 \\
0.359 & 0.389 & 0.241 & 0.011 & 0 \\
0.372 & 0.405 & 0.223 & 0 & 0
\end{array}\right] \\
& R_{4}=\left[\begin{array}{ccccc}
0.36 & 0.399 & 0.241 & 0 & 0 \\
0.312 & 0.375 & 0.293 & 0.02 & 0 \\
0.309 & 0.371 & 0.290 & 0.03 & 0 \\
0.341 & 0.385 & 0.263 & 0.01 & 0
\end{array}\right] \quad R_{5}=\left[\begin{array}{ccccc}
0.407 & 0.401 & 0.192 & 0 & 0 \\
0.387 & 0.406 & 0.207 & 0 & 0 \\
0.375 & 0.409 & 0.216 & 0 & 0
\end{array}\right]
\end{aligned}
$$

The paper definites grey comprehensive evaluation weight vector, that is $M=\omega_{0} \cdot Z=\left[\begin{array}{lllll}0.389 & 0.397 & 0.21 & 0.004 & 0\end{array}\right]$

The general grey evaluation matrix is

$$
Z=\left[\omega_{i} \cdot R_{i}\right]=\left[\begin{array}{ccccc}
0.432 & 0.396 & 0.172 & 0 & 0 \\
0.416 & 0.399 & 0.185 & 0 & 0 \\
0.371 & 0.4 & 0.225 & 0.004 & 0 \\
0.328 & 0.381 & 0.274 & 0.017 & 0 \\
0.389 & 0.406 & 0.205 & 0 & 0
\end{array}\right]
$$

It is concluded that the comprehensive result for the integrated evaluation of emergency management capability is $W=M U=7.432$.It belongs to the good grade and fails to reach the very good grade according to evaluation index value of management performance in table1. Similarly, the evaluation results of the second layer index are $W_{1}=7.60, W_{2}=7.5, W_{3}=6.68, W_{4}=6.4, W_{5}=7.29$. The lowest score is $W_{3}, W_{4}$, so it is the primary object to be improved.

\section{Conclusions}

(1) the C-OWA operator is used to determine the weights of the indexes, and the data can be re assembled in the calculation process, which effectively weakens the adverse effects of the extreme values of the decision data, and makes the weight of the measurements more reasonable.

(2) the emergency management capability evaluation system of subway construction has relative grey characteristics, but the grey system theory can solve the problem of few grey information samples and poor data, and obtain the emergency management ability level of each stage.

(3) the quantitative evaluation of emergency management capability by grey theory is not only applicable to the emergency management of metro construction stage, but also to other aspects of subway construction. The method provides a scientific and effective evaluation method for the evaluation of the emergency management ability of Metro construction.

\section{References}

[1] LU.W.G, PENG.J, The Study of Capability Assessment for metro Emergency System on Guangzhou, Urban Studies. (2012),04:118-124.

[2] WANG.Q.K, Design of Emergency Management Information System for Metro Engineering Construction, C Journal of Huazhong University of Science and Technology, (2011),02:67-72.

[3] Han. J: Research on the Emergency Preparedness Plans of the Urban metro (2010)

[4]Zheng.Y.F,Jiang.T.H,Kappa Analysis on Assessment of urban Emergency Capability.China Safety Science Journal.(2006) 
[5] ZHOU.L.G,CHEN.H.Y,WU.X.F,WEI.D, A Method of Interval Number Group Decision Making Based on the Combined Uncertain OWA Operator, College Mathematics ,(2011),02:52-56. 